\title{
Determining the learning preferences of the students of the faculty of health sciences in Cyprus International University
}

\author{
S.Yaprak Cetin ${ }^{1, *}$ and Suat Erel $^{2}$ \\ ${ }^{1}$ Akdeniz University, Department of Physiotherapy and Rehabilitation, Antalya, 70002, Turkey \\ ${ }^{2}$ Pamukkale Univesity, School of Physical Therapy and Rehabilitation, Denizli, 20160, Turkey
}

\begin{abstract}
The purpose of the study is to examine the learning preferences of students at the Cyprus International University of Health Sciences and determine whether these preferences have changed according to department and sex. A total of 150 students participated in the study. While 61 of the students were female and 89 were male, the mean age was $22.06 \pm 1.23$ years. VARK [Visual, Aural, Read-write, Kinesthetic] Learning Preferences Inventory was used to determine students' learning preferences. As a result of the study participants mostly found "Kinesthetic" style $(4.84 \pm 2.13)$. However, there were no significant differences in terms of department and gender factors in any dimension ( $\mathrm{p}>$ 0.05 ). Based on the results of this study, we think that determining the learning style that students are likely to lead to the selection of suitable techniques for the trainees.
\end{abstract}

Keywords: Learning preferences, students, health sciences faculty

\section{Introduction}

Students can learn in many ways [1]. Some students learn by seeing, some learn by hearing whereas some of them learn by drawing and creating mathematical models. Students from all age groups have ways of responding differently but coherently to the phenomenon of learning. These behaviors are called learning style or cognitive style [2]. In other words, the style of learning is a way of preserving new and difficult knowledge that begins with concentration, is processed and adopted. Methods of learning are also diverse. The amount of learning achieved by a student during class depends not only on that student's natural skills and preparation for the class but is also related to the student's style of learning and the educator's teaching method [3].

Educators are in pursuit of various strategies for their course sessions. As educators improve themselves in this direction, the quality of education increases [2].A student's determination and awareness of his/her own learning style, ensures better deliberation in the

\footnotetext{
* Corresponding author: fzt_s.yaprakulgen@hotmail.com
} 
selection of materials, and in course design among the educators for improving the learning opportunities [1].

There is a variety of measuring tools in order to determine the learning style of a student. Developed by Fleming, the VARK [V: visual, A: aural, R: read-write, K: kineshtetic] model ofers a profile of students that enables the reception of knowledge and is based on sensual modalities. According to this model, students that prefer the visual style process knowledge through seeing. Students that prefer the aural style receive knowledge through hearing. For the read-write option, students prefer words to be written down. And the students that prefer the kinesthetic style acquire knowledge through experimentation and practice [2].

In literature, there are studies on learning preferences of students receiving education in a variety of fields $[4,5,6,7,8]$. Recent studies on students receiving education in the area of health are most generally carried out among faculties of medicine and faculties of nursing [7-10]. According to the results of these studies, it was observed that students studying in different departments have different learning styles [4-10). In these studies, it is also indicated that gender difference is a significant factor in terms of learning preference [11-13]. Additionally, in literature, there are also a few studies comparing the learning preferences among different departments $[6,14]$.

The aim of this study is to determine the learning preferences of the students receiving education at Physical Therapy and Rehabilitation, Nutrition and Dietetics and Nursing departments within the faculty of health sciences and to detect whether such preferences differ according to the varieties of grade and gender.

\section{Methods}

\subsection{Participants}

The population of the research comprises of the students receiving education at Cyprus International University, Faculty of Health Sciences. The criteria of inclusion in the research necessitate being enrolled in one of the departments of Physical Therapy and Rehabilitation, Nutrition and Dietetics and Nursing departments within the faculty of health sciences, as well as volunteering to participate. The criterion of non-inclusion is he filling out the questionnaire incompletely.

A total of 150 students in the Cyprus International University of Health Sciences Faculty in Physiotherapy and Rehabilitation [n:50], Nutrition and Dietetics [n:50], Nursing [n:50] department attending the 3rd and 4th semester in 2017-2018 academic year participated in the study. While 61 of the students were male and 89 were female, the mean age was $22.06 \pm 1.23$ years.

\subsection{Procedure}

VARK [Visual, Aural, Read-write, Kinesthetic] Learning Preferences Inventory was used to determine students' learning preferences. This test was developed by Fleming in 1987 and was later adapted to Turkish by Kalkan $[15,16]$.

The scope of VARK inventory is defined as follows: the students that prefer learning in visual style make use of body language, mimics, diagrams, maps, graphics, pictures and tables in order to understand the contents of a course. The students that prefer aural tyle learning give importance to music and aural stimulants. Speaking, discussion, listening, narrating, tone fo voice and speaking speed are important for students that prefer this style. The students that prefer the read-write style garther information by reading or writing from 
published materials. The students that prefer the kinesthetic style learn through moving, touching and doing [17].

The VARK inventory consists of 16 questions in total. In the inventory, a different scenario is created for each question and the individual is asked about what action $\mathrm{s} / \mathrm{he}$ would take in that scenario. The individual that prefers multiple ways can mark more than one option. The responses to the inventory questions are graded according to their being visual, aural, read-write and kinesthetic and total grades are obtained in these four dimensions. A higher grade in a dimension indicates that the related learning style is preferred on a higher degree [15]. A student responding to the questionnaire can prefer more than one learning style; and this reveals that an individual can be inclined to multidimensional learning style.

\subsubsection{Statistical Analysis}

The results of the study were analyzed with the SPSS 16.0 [Statistical Package for the Social Sciences] software. During this assessment, definitive statistics such as mean value, standard deviation and frequency distribution were used. Whether the data is coherent with the normal distribution was determined by use of the Kolmogorov Smirnov Test. The oneway analysis of variance "ANOVA" was used for comparing the department variables of the data whereas "Independent Samples T-Test" was used for the gender variable. Significance level was accepted as $\mathrm{p}<0.05$.

\section{Results}

Demographic data of the students are presented in Table 1.

Table 1. Demographics data of students

\begin{tabular}{|c|c|c|}
\hline & $\mathbf{X} \pm$ SD & min-max \\
\hline Age (years) & $22.26 \pm 1.27$ & $21-27$ \\
\hline Weight (kg) & $62.07 \pm 13.09$ & $48-93$ \\
\hline Height (cm) & $168.53 \pm 11.14$ & $158-182$ \\
\hline Gender & $\mathbf{\%}$ & $\mathbf{n}$ \\
\hline Female & 59.3 & 89 \\
Male & 40.7 & 61 \\
\hline
\end{tabular}

It was found that the students mostly prefer the "Kinesthetic [K]" style [Table 2]. It was found that the students receiving education at Physical Therapy and Rehabilitation and Nursing mostly prefer the "Kinesthetic [K]" style; whereas the students at Nutrition and Dietetics prefer the "Aural [A]" style. 
Table 2. Means of VARK's dimensions

\begin{tabular}{|c|c|}
\hline VARK & $\mathbf{X} \pm$ SD \\
\hline Visual & $3.38 \pm 2.08$ \\
\hline Auditory & $4.53 \pm 1.77$ \\
\hline Read-write & $4.01 \pm 1.76$ \\
\hline Kinesthetic & $4.84 \pm 2.13$ \\
\hline
\end{tabular}

$\mathrm{X}:$ mean, SD:Standart deviation

However, when the learning preferences were compared among the departments, a statistically meaningful difference could not be detected in any of the learning style dimensions [Table $3, \mathrm{p}<0.05$ ].

Table 3. Comparison between of departments of learning styles

\begin{tabular}{|c|c|c|c|c|c|}
\hline VARK & $\begin{array}{c}\text { Physitherapy } \\
\mathbf{X} \pm \text { SD }\end{array}$ & $\begin{array}{c}\text { Nutrition and } \\
\text { dietetics } \\
\mathbf{X} \pm \text { SD }\end{array}$ & $\begin{array}{c}\text { Nursing } \\
\mathbf{X} \pm \text { SD }\end{array}$ & $\mathbf{F}$ & $\mathbf{p}^{*}$ \\
\hline Visual & $3.22 \pm 2.12$ & $3.68 \pm 1.80$ & $3.26 \pm 2.30$ & 2.64 & .07 \\
\hline Auditory & $4.32 \pm 1.75$ & $4.76 \pm 1.97$ & $4.52 \pm 1.58$ & 0.18 & .82 \\
\hline Read-write & $3.84 \pm 1.73$ & $4.30 \pm 1.82$ & $3.90 \pm 1.72$ & 0.72 & .48 \\
\hline Kinesthetic & $5.02 \pm 2.12$ & $4.52 \pm 2.19$ & $4.98 \pm 2.08$ & 0.09 & .90 \\
\hline \multicolumn{7}{|c}{$*$ ANOVA, $\mathrm{p}<0.05$, X:mean, SD:Standart deviation }
\end{tabular}

When the learning preferences were compared according to gender, a statistically meaningful difference could not be detected in any of the learning style dimensions [Table $4, \mathrm{p}<0.05]$.

Table 4. Comparison of dimensions of VARK in terms of gender

\begin{tabular}{|c|c|c|c|c|}
\hline \multirow{2}{*}{ VARK } & \multicolumn{2}{|c|}{$\mathbf{X} \pm$ SD } & \multirow{2}{*}{ F } & \\
\cline { 2 - 3 } & Female & Male & & .08 \\
\hline Visual & $3.73 \pm 2.04$ & $3.14 \pm 2.08$ & 0.09 & .49 \\
\hline Auditory & $4.40 \pm 1.97$ & $4.61 \pm 1.62$ & 0.18 & .16 \\
\hline Read-write & $3.77 \pm 1.75$ & $4.17 \pm 1.75$ & 0.11 & .50 \\
\hline Kinesthetic & $4.70 \pm 1.79$ & $4.93 \pm 2.34$ & 2.47 & \\
\hline
\end{tabular}

*Independent sample T test, $\mathrm{p}<0.05 \mathrm{X}$ :mean, SD:Standart deviation

\section{Discussion and Conclusion}

As a result of the study, it was observed that the students most generally prefer the "Kinesthetic [K]" style. It was found that the students receiving education at Physical Therapy and Rehabilitation and Nursing prefer the "Kinesthetic [K]" style; whereas the students at Nutrition and Dietetics prefer the "Aural [A]" style. However, the scale among the department did not reveal any meaningful difference. Similarly, in the comparison among departments and gender, a meaningful difference could not be detected in any dimension of the scale. 
In literature, there are studies on learning preferences of students receiving education in a variety of fields (4-10). In a study in Iran carried out among medical students, it was found that the learning preference of students is Aural and Read-Write [9]. In another study, it was found that the students receiving education at the faculty of health sciences prefer the "Kinesthetic" style. The results obtained from this study have similarities with the study carried out by Baykan et. al [18]. We are in the opinion that this result depends on the fact that the courses at the faculty of health sciences are practical and require clinical experience $[14,18]$.

In the literature, the results of the studies related to the comparison of learning preferences according to the gender are contradictory. In a study carried out with the students of Faculty of Medicine, in the Visual dimension, a meaningful result was found among female students [19]. In another study with the students at faculty of medicine, a gender difference could not be detected in any dimension of the VARK inventory. In a study carried out at a faculty of health sciences, a meaningful result was obtained among male students in the Kinesthetic style of the VARK inventory [18]. In a study with the dental school students, a difference according to gender could not be found [20]. In our study, a gender difference could not be found in any of the sub-dimensions of the VARK inventory. When the departments included in our study were compared with those in the study of Baykan et. al., a similarity was detected only with the Physical Therapy and Rehabilitation department. However, in this study, a different result among genders is not provided for the Physical Therapy and Rehabilitation department.

In literature, the results of the learning preferences of the students receiving education at different departments are diverse. In the studies, it was observed that the students at Physical Therapy and Rehabilitation department mostly prefer the Kinesthetic style [14]. According to the studies carried out with Nursing students in various universities, it was observed that the students prefer the kinesthetic style [21,22]. In another study, it was found that the physical therapy and nursing students also prefer kinesthetic style [23]. No study that determines the learning preferences of Nutrition and Dietetics students could be found in literature. In our study, in parallelism with the literature, it was found that physical therapy and rehabilitation and nursing students prefer the Kinesthetic style. In our opinion, the fact that the learning style of the nutrition and dietetics students is different is because the contents of the courses taught in this department are based mostly on theory.

The limitation in our study is the inequality of the number of male and female students. Another limitation is that in these departments, only the $3^{\text {rd }}$ and $4^{\text {th }}$ grade students were included in our study and that these students were taken as a single group and the differences among the grades was not taken into consideration.

According to the results of our study, the students receiving education at the faculty of health sciences most generally prefer the Kinesthetic style. Based on these results, it would be convenient for the educators at the faculty of health sciences to develop techniques according to this style while preparing the contents of their courses. Determination of the style that is mostly preferred by students could provide guidance for educators in selecting the right teaching technique. Thus, an increase in student achievements in their department courses can be provided.

\section{References}

1. R.M. Felder, L. K. Silverman. Learning and teaching styles in engineering education. Engr Education, 78, 674-81 (1988)

2. N. D. Fleming, C. Mills. Not Another Inventory, Rather a Catalyst for reflection. To Improve the Academy, 11, 137-55 (1992) 
3. T. F. Hawk, A. J. Shah. Using learning style instruments to enhance student learning. Dec Sci J Innov Edu, 5, 1-19 (2007)

4. S. Tuna. The Learning Styles of Art Education Students. Electro J Soc Sci, 25, 252-261 (2008).

5. H. H. Bahar, R. Polat, M.R. Ozbas, Learning Styles of Art, Music and Physical Education Pre-Service Teachers. J Edu Fac, 18, 409-424 (2016)

6. T. Brown, T. Cosgriff, G. French. Learning style preferences of occupational therapy, physiotherapy, and speech pathology students: a comparative study. J Allied Health, 6,3 (2008)

7. P. Kharb, P. P. Samanta, M. Jindal, V. Singh. The learning styles and preferred teaching-learning strategies of first year medical students. J Clin Diagn Res. 7, 6, 10891092 (2013).

8. I. M. Alkhasawneh, M.T. Mrayyan, C. Docherty, S. Alashram, H. Y. Yousef. Problembased learning (PBL): assessing students' learning preferences using VARK. Nurse Educ Today, 28, 5, 572-579 (2008).

9. H. Peyman, J. Sadeghifar, M. Alizadeh, M. Yaghoubi, M. Mohammad Hassan Nahal, N. Yamani, et al. Learning Styles of First Year Nursing and Midwifery Students in Ilam University of Medical Sciences. J Med Educ, 11, 9, 1350-1358 (2012).

10. T.A. Meehan-Andrews. Teaching mode efficiency and learning preferences of first year nursing students. Nurse Educ Today, 29, 1, 24-32 (2009).

11. R. Choudhary, P, Dullo, R.V. Tandon. Gender differences in learning style preferences of first year medical students. Pak J Physiol 7,2 (2011).

12. E. A. Wehrwein, H. L. Lujan, S. E. DiCarlo. Gender differences in learning style preferences among undergraduate physiology students. Adv Physiol Educ. 31, 2 ,153157 (2007).

13. R. P. Urval, A. Kamath, S. Ullal, A. K. Shenoy, N. Shenoy, L. A. Udupa. Assessment of learning styles of undergraduate medical students using the VARK questionnaire and the influence of sex and academic performance. Adv Physiol Educ, 38, 216-220 (2014).

14. S. A. Karaborklu, R. Mustafaoglu, G. Kus, A.R. Ozdincler. Determination of Learning Style Preferences in Students at the Faculty of Health Sciences. Clin Exp Health Sci, 7, 146-151 (2017).

15. N. Fleming. VARK: A guide to learning styles Retrieved August 27, 2009, Available from: http://www. vark-learn. com/english/page. asp? $\mathrm{p}=$ research. (2001).

16. M. Kalkan. Learning preferences and problem-based discussion sessions: a study with Turkish university maritime students, SBPJ 36, 1295-1302 (2008).

17. N. Fleming, C. Mills. Not another inventory, rather a catalyst for reflection, To improve the academy, 11, 137 (1992).

18. Z. Baykan, M. Nacar. Learning styles of first year medical students attending Erciyes University in Kayscri,Turkey. Adv Physiol Educ. 31,158-160 (2007).

19. R.S.Y. Wong, H.L. Siow, V. Kumarasamy, N.S.F. Suhaimi. Interdisciplinary and inter-institutional differences in learning preferences among Malaysian medical and health sciences students. J Adv Med E, 5, 4, 164-171 (2017).

20. Z. Nasiri, S. Gharekhani, M. Ghasempour. Relationship between Learning Style and Academic Status of Babol Dental Students. Electron Physician. 8, 5, 2340-2345 (2016). 
21. L. McKenna, B. Copnell , A.E. Butler, R. Lau, Learning style preferences of Australian accelerated postgraduate pre-registration nursing students: A cross-sectional survey. Nurse Educ Pract, 28, 280-284 (2018).

22. B.V. Stirling. Results of a study assessing teaching methods of faculty after measuring student learning style preference, Nurse Educ. Today. 55, 107-111 (2017).

23. J.P. Good, D. Ramos , D.C. D'Amore. Learning style preferences and academic success of preclinical allied health students. J Allied Health. 42, 4,81-90 (2013). 